definite rules and were, in nearly all cases, most unsatisfactory. Photometry was then regarded by most people as merely an interesting hobby. In the value now attached to this most fundamental subject the Illuminating Engineering Society and its journal have played a most important part. Government Committees such as the Illumination Research Committee working under the Department of Scientific and Industrial Research are now in existence and doing, as our readers are aware, excellent work, but the pioneers were the Illuminating Engineering Society. The Chairman of our own Editorial Committee, a Past-President of the Society, in his congratulatory note draws attention to the great debt owed by both illuminating engineers and the medical profession to the late editor for his constant efforts to bring them together and facilitate the solution of problems in which they are jointly interested, and also to The Illuminating Engineer for acting as the medium by which the results of such researches are made widely known. In offering our congratulations to our contemporary we venture to express our confident hope that the future will be as productive of good work as the past twenty years have been.

\title{
Ophthalmic Benefit and Clinics
}

A letter appears in the supplement of the British Medical Journal of February 18, 1928, over the signature M.D., D.O.M.S., which deserves attention. The writer draws attention to the fact that not all the cases in the ophthalmic benefit scheme work out at the simple refraction for a guinea. Of his own cases for the month of January under the scheme, only half were cases of refraction; the others were of diverse kind, many of them had to be seen more than once and some of them frequently. His cases included two Meibomian cysts, which had to be evacuated under cocaine; an abrasion of the cornea, seen four times; a severe interstitial keratitis, seen twelve times to date; acute iritis, seen ten times; angular conjunctivitis and blepharitis, seen thrice; chronic glaucoma, operation, seen seven times at home, besides hospital attendance; severe irido-cyclitis, seen six times to date; a .deep septic corneal ulcer, seen twice to date; two patients with neglected foreign bodies on the cornea, both cases with marked infection, which necessitated numerous attendances.

The glaucoma case had already been to two opticians, the second time having been sent by his society. In course of time the writer hopes to receive a guinea for his work from the society, which might us he says, have had to pay the man sick benefit for years. The writer estimates that he has received anything from eighteenpence to a guinea per attendance, and that in his case, a total of sixty- 
three attendances divided into twenty-two possible guineas works out at something under $\mathrm{is}$. an attendance for the average, but is really less as some of the cases are not finished. Also the acute cases have to be seen and treated as emergencies, the application for benefit being sent in after the patient's attendance. In some of these cases the benefit may be refused. The writer quotes such a case. Some writers have suggested reducing the fee to $10 / 6$ per case. In the writer's case the average time for the attendances would be twenty minutes to half an hour; and the suggested fee, in cases which have to be seen many times is absurd. He says: "is it surprising that some of us feel inclined to withdraw our names at once, and see patients who are poor, and sent by their doctors, in the old way?" We are under the impression that the ophthalmic benefit scheme was intended primarily to-cover the provision of spectacles; and that most of the acute cases outlined by the writer of this letter, were calculated as fit and proper cases for hospital treatment. But this does not affect the point which he raises; for it is obviously to the patient's advantage, to continue under the treatment of such a one as the writer who has the special knowledge and even hospital facilities for treatment. Not all those on the ophthalmic panel, are we believe, capable of performing an operation for glaucoma. In the cases where the panel practitioner has the requisite knowledge and ability, he stands the chance of being overwhelmed with work of this kind at a very inadequate remuneration.

\section{The British Journal of Ophthalmology}

\section{ReCENT DeVelopments}

In the January number we drew attention to recent developments on the part of the journal. These were concerned with monograph supplements and the publication of books. We are now pleased to be able to add that the continued prosperity of the journal has enabled the Board of Directors to assent to a proposal for furthering research, details of which will be found below. It is to be hoped that the proffered scheme of assistance will enable those of our contributors who are in a position to undertake research work to make valuable additions to our knowledge.

The British Journal, of Ophthalmology is prepared to assist research work in ophthalmology by granting subsidies towards the expenses of research to those qualified to undertake such work.

The qualifications of the applicant, the subject of the research, and the place where the work is to be carried out, must be submitted for approval to the Editorial Committee. The applicant must give 